\title{
Effects of Using the Online Dictionary for Etymological Analysis on Vocabulary Development in EFL College Students
}

\author{
Abdulaziz Ibraheem Fageeh \\ Faculty of Sciences and Arts at Tanouma, King Khalid University, KSA
}

\begin{abstract}
This study has been designed to investigate the effects of using the Online Dictionary for presenting etymological analysis of new vocabulary items in hyperlinked words to students in an online environment, using the accompanying facilities of thesaurus, encyclopedia, and web on developing vocabulary building skills and inducing positive attitudes towards vocabulary learning in EFL students of the College of Languages and Translation, Abha. The study employs a triangulation of research methods, in which two groups studying Vocabulary II, one in traditional setting (control) and the other (experimental) via the Online Dictionary's etymological analysis feature in a Blackboard environment are examined for the development of vocabulary learning skills and their attitudes towards etymological analysis. The study bore out findings in favour of the new technique of vocabulary learning, i.e., etymological analysis, powered by the Online Dictionary in improving vocabulary learning and inducing to positive attitudes towards vocabulary instruction. The results are discussed in relation to the hypotheses and against the research backdrop presented in the review of the literature. The study ends on a set of pedagogical implications and recommendations for further research.
\end{abstract}

Index Terms - vocabulary learning, etymology, retention, Blackboard, dictionary learning, semantic mapping, glossing

\section{INTRODUCTION}

Learning vocabulary is an incremental and developmental process that starts with foreign language learning. Researchers revealed that the average foreign language learners acquire the meanings of about 6,000 root words in a matter of two years, or about 2.4 root words per day (e.g., Anglin, 1993; Biemiller, 2005, 2006; Biemiller \& Slonim, 2001). The more the foreign language learner moves with the learning process actively, the more the need is for acquiring more vocabulary. But English as a foreign language learners require a threshold of 5000 word families to be able to be independent EFL learners, however (Coady, 1997). Researchers further maintain that EFL learners require from 450,000 to 750,000 to be able to develop reading comprehension and writing skills and to achieve academically better (Stahl, 1999; Tompkins, 2005).

Paul (1996) claims that overt vocabulary instruction is a must, particularly for poor readers, who are not likely to derive word meanings from the use of context while reading. One of the most effective instructionally remedial strategies for enhancing vocabulary learning and reading comprehension is for learners to use dictionaries. Dictionaries can be monolingual, in which case the target words are defined in the language of the target words, or bilingual, in which the target words are defined in a second language that matches the first language of the user. Studies have demonstrated that the majority of L2learners use such bilingual dictionaries regardless of their proficiency level (Jian, Sandnes, Law, Yo-Ping Huang, \& Huang, 2009; Kent, 2001; Laufer \& Hadar, 1997; Laufer \& Rimmel, 1997).

Dictionaries are now readily available both as paper or electronic (e-dictionaries). E-dictionaries maybe either online (e.g., the website Dictionary.reference.com), which can also be available apps for portable devices, and smart mobile phones, and can be efficiently used to facilitate reading comprehension and vocabulary acquisition for adult learners of a second/foreign language (Ji, 2009; Mekheimer, 2012; Shi, 2008; Welker, 2010; Zhang, 2000). The use of edictionaries in foreign language learning settings has been reported to facilitate reading comprehension and vocabulary enhancement (Knight, 1994; Koga, 1995; Mekheimer, 2012), often better than paper dictionaries (Koga, 1995; Laufer, 2001; Mekheimer, 2012). Chen (2011) investigated the effects of paper-based bilingual dictionaries versus online edictionaries and concluded that the use of the latter exponentially improved learning and retention of unknown words encountered during a reading, with e-dictionaries providing a comparatively stronger learning effect than paper dictionaries. In the same way, Dziemianko (2010) revealed that e-dictionary use is better than paper dictionary use for learning. Furthermore, Dziemianko (2011) found that a comparison of paper-based versus online dictionaries bore no such significantly positive effects to the good of e-dictionaries; this was ascribed to the difference in the outlook and interface of the e-dictionaries that were used in the study of Dziemianko (2011), as the website in this study was messy with banners and widgets, in contrast to the clean, orderly look of the original study's website in the study of 2010. In this vein, too, e-dictionaries were also found to exercise an enhancing effect on reading comprehension of intermediate readers to a level tantamount to that of advanced readers (Wang, 2011). As for attitudes towards using which media, 
paper format or the e-format of dictionaries, research has borne out findings that support the hypothesis that edictionaries are the most favourite media of today's adult students (Noor, 2011; Mekheimer, 2012).

The reason for this preference has been attributed in an investigation by Aldosari \& Mekheimer (2010) which revealed that EFL learners "utilise all available information provided by the online dictionary before deciding on the meaning of the new word" seem to have made the most use of an online dictionary in the electronic milieu (p.550).

The online dictionary manipulated for this study enjoys the facilities of thesaurus, encyclopedia, translator, and web. One feature of lexical presentation in this online dictionary is the provision of etymological analysis at the end of the entries. According to one study by Bellomo (1999), etymology instruction was useful for learners who were given explicit instruction. More recent studies could prove that the use of semantic mapping strategy as a vocabulary presentation technique, which is also a feature in the Online Dictionary, as well as the use of etymological analysis could lead to improved vocabulary retention and improved reading comprehension (Baleghizadeh and Yousefpoori Naeim, 2011; Hosseini, Sarfallah, Bakhshipour \& Dolatabadi, 2012).

The purpose of the present study, therefore, was to examine the effects of using the Online Dictionary for etymological analysis for improving vocabulary learning and retention. Therefore, the research question that arises from this purpose is:

What are the effects of the Online Dictionary on developing vocabulary learning and retention in EFL students of the College of Languages and Translation in Abha?

\section{LITERATURE REVIEW}

Methods and techniques of vocabulary learning and teaching to promote efficient and effective vocabulary acquisition have been worthwhile lines of research in ESL/EFL. Available literature points to two main approaches to vocabulary learning and teaching: the implicit and the explicit approaches. Vocabulary research indicates that the majority of our mental lexicon is more likely to be acquired incidentally and is implicitly stored in subtle ways. Incidental vocabulary is the off-shot of implicit teaching methods geared towards facilitating vocabulary learning. Intentional learning, however, requires laying emphasis, during instruction, on linguistic forms, whereas incidental learning needs rapt attention to be directed to meaning while paying peripheral attention to forms. In explicit vocabulary learning, students get involved in activities that emphasise vocabulary learning per se. In this vein, Allen (1983) maintains that the explicit approach to vocabulary instruction should be adopted by utilizing a variety of vocabulary learning strategies commensurate with the learning and cognitive styles of the students.

There are varied vocabulary learning strategies (VLSs) have attracted the attention of many researchers around the world (Ahmed, 1989; Sanaoui, 1995; Gu and Johnson, 1996; Lawson and Hogben, 1996; Schmitt, 1997; Kojic-Sabo and Lightbown, 1999; Nakamura, 2002; Catalán, 2003; Fan, 2003; Gu, 2003).

The use of such varied techniques of vocabulary instruction is a must for language learners and teachers alike to help the former to compensate for their limited lexical competences (Nyikos and Fan, 2007) and to ensure that teaching methods of vocabulary cater to the needs of limited vocabulary learners on the part of the latter (Zaid, 2009). This is especially required in EFL settings where exposure to the English lexicon in daily life is extremely limited as is the case in Saudi Arabia.

Research on strategy-based instruction for vocabulary building is informed by the depth-of-processing theory (Craik andLockhart, 1972) in which 'deeper' processing is construed as being superiorto 'shallow' processing. Therefore, a significant feature of VLSs instruction lies in the inclusion of metacognitive strategies. Research indicates that the effect of explicit metacognitive strategy training is conducive to enhanced vocabulary learning (Rasekh and Ranjbary, 2003; Zaki and Ellis, 1999). This cognitively structured approach to vocabulary learning is significantly important to give fruition to improved lexical learning (Sanaoui, 1995; Folse, 2004; Zaid, 2009; Zaki and Ellis, 1999).

However, vocabulary strategy instruction research suggests that this approach can be most successful when incorporated into the regular classroom instruction (McDonough, 1999).Two important cognitive techniques used to improve the progress of vocabulary teaching and learning are glossing and hyperlinking which can aid foreign language learners to study and develop vocabulary and better achieve on reading comprehension tasks (Dwight, 2003; Lomika, 1998; Nikolova, 2004). Prior research indicates that providing links to electronic dictionaries or to glosses that explain new vocabulary in the target language allow for reading with less distraction and greater understanding and retention of new knowledge compared with the slower process of looking in paper-based reference tools (Solomon, 2002; Koponen, 2012). In addition, prior research indicates that glossing or hyperlinking to clarifying sources increases knowledge acquisition and retention (Dwight, 2003; Lomika, 1998; Nikolova, 2004).

In addition, explored the relationship between the use of computerized dictionaries/online glossing and vocabulary acquisition and overall reading comprehension (Aweiss, 1994; Chun \& Plass, 1996; Gettys, Imhof, \& Kautz, 2001; Knight, 1994; Lomika, 1998; Lyman-Hager, Davis, Burnett, \& Chennault, 1993). Lyman-Hager et al. (1993) examined the effects of using computerized dictionaries on vocabulary acquisition; findings showed that glossed vocabulary instruction resulted in a higher retention rate. By the same token, Aweiss (1994) explored the effect of computermediated reading supports on comprehension during independent reading. The most significant finding of the study showed that readers with access to computer-assisted reading aids scored significantly higher on the immediate recall protocol than those with no access to any reading aids. 
The use of etymological analysis and semantic mapping can be conducive to enhanced vocabulary acquisition. In this way, Schmitt (2008) maintains that "the overriding principle for maximizing vocabulary learning is to increase the amount of engagement learners have with etymological items, mainly the roots"(p.352) which could be done using online dictionaries that provide etymological references to their entries and semantic maps that show the development of the words (Hosseini, et al., 2012). Therefore, Trench (1998) views etymological analysis as a significant technique in the presentation of new vocabulary to foreign language learners and considers explicit etymology teaching as a mustread feature of entries in dictionaries.

The present researcher defines the etymological analysis strategy as a useful presentational strategy of vocabulary instruction through their comprising roots and identifying word origins attributable to classic languages.

Yet, research on the effects of etymological analysis is scant (Hosseini, et al., 2012). According to Hosseini, et al. (2012), the use of etymological analysis through online dictionaries can be conducive to improved findings regarding vocabulary learning and positive effects on the opinions of learners regarding the use of this technique for the study of vocabulary. In this vein, too, Baleghizadeh and Yousefpoori Naeim (2011) indicated that the use of semantic mapping strategies can lead to improved word retention and better vocabulary acquisition. By the same token, Bellomo (1999), examined the effects of etymology instruction and concluded that teaching affixes, morphological analysis and etymological analysis can result in improved explicit instruction and learning of vocabulary through teaching etymologies, semantic mapping and the use of meaningfully contextualised words.

\section{METHODOLOGY}

\section{Method}

The study employs a triangulation of research methods, including experimental designs and descriptive introspection of opinions towards effectiveness of learning vocabulary through etymology and the quality of retention of learned vocabulary; two groups studying Vocabulary II, one in the traditional setting (control) and the other (the experimental) via Blackboard are tested for their vocabulary learning and retention mean scores upon using the traditional medium of instruction (teacher-centred, paper dictionary-based, and classroom-oriented) and the technology-based medium of Blackboard (Blackboard-oriented, online dictionary-based, and in virtual classrooms).

\section{Participants}

The sample of the study consisted of 83 male students enrolled in the English department, College of Languages \& Translation, Abha, KKU, in Levels VII VIII.

\section{Instruments}

A multiple-choice vocabulary test was developed for the purpose of the present study. This multiple-choice test of vocabulary was comprised of 100 items selected from the text book before it was piloted. These items were piloted with 25 students at the same level of the intact group of participants harnessed for the present study. Then, after data collection, the process of item analysis was carried out. Too difficult and too easy items were discarded, some were modified, and there eventually remained 50 items which were used for the pre-test and post-test in this study for experimental and control groups. The reliability of the test was calculated using the Cronbach Alpha co-efficient formula ( $r=0.86$ - a coefficient deemed appropriate for an aptitude test).

In addition, an introspective survey, which consisted of five statements, was designed in order to check the participants' opinions concerning the effectiveness of learning vocabulary through etymology and the quality of retention of learned vocabulary items. This survey focused on assessing the degree to which teaching and learning new vocabulary items through etymology affect the development of EFL learners' knowledge of lexicon and its retention by lapse of time. The scale was validated by a jury of 8 assistant professors, 3 professors, and 5 associate professors of Translation, TEFL, and Applied Linguistics in KKU. The reliability coefficient of the scale using Cronbach Alpha was $(\alpha=0.94)$ which is an appropriate value.

\section{Materials}

For both groups of the research, the set book of Vocabulary II was used as a main material for instruction.

\section{Hypotheses of the Study}

1. There are no statistically significant differences between the vocabulary test mean scores of the control group and those of the experimental group attributable to the medium of instruction (the paper-based dictionary, the Longman Dictionary of Contemporary English, versus the online dictionary, the website Dictionary.com).

2. There are no statistically significant differences between the opinions concerning the effectiveness of learning vocabulary through etymology and the quality of retention of learned vocabulary items survey mean scores of the control group and those of the experimental group attributable to the medium of instruction.

\section{Procedures}

The participants of this study were divided into two groups: the experimental and the control. The vocabulary test was administered to the two groups to elicit evidence in order to compare with the posttest results and to ensure that both groups were equal at the onset of the study. Then, the students of both groups received their instruction via a teacher-centred, paper dictionary-based, and classroom-oriented approach for the control group and the Blackboardoriented, online dictionary-based approach for the experimental group respectively. During the experimental treatment, the experimental group received instruction on etymological analysis of vocabulary via the etymology feature of the 
Online Dictionary in 48 sessions during 16 weeks in the academic year 2012-2013. During the treatment also, they were requested to read selected extra texts with unfamiliar vocabulary items that have varied etymologies (from French, Latin, Greek, Arabic, etc.). The experimental group students were thus given access to the etymological analysis of new words used in the passages via links to the Online Dictionary. They were actually taught to learn unfamiliar words using their root meaning presented in Online Dictionary. They were also requested to drill the learned roots and their meanings by giving examples of words with the same roots.

On the other hand, the control group students received the same materials but they were instructed into the new vocabulary through the traditional way of vocabulary teaching through bilingualised English-Arabic word lists in 48 sessions over the period of the semester. In some classes, students in the control group were required to infer the meaning of the unfamiliar words from the text or use the paper-based dictionary to look them up. After 16 weeks, the experimental and control groups both were given the same posttest of vocabulary to explore the effects of the two different media of vocabulary instruction. Finally, after the administration of the posttest, the effectiveness of learning vocabulary through etymology and the quality of retention of learned vocabulary survey was given to the participants in order to glean their opinions regarding the effectiveness of employing etymological analysis as a medium of vocabulary acquisition.

\section{RESUlts}

The researcher implemented the experiment during the second semester of the academic year 2013 started in midJanuary and ended in mid-May, 2013. To control for group equivalence, a t-test was calculated to compare mean scores of both groups on pretesting vocabulary knowledge and retention as shown in Table (1) below:

TABLE 1

GROUP EQUIVALENCE OF CONTROL AND EXPERIMENTAL PARTICIPANTS ON VOCABULARY KNOWLEDGE AND RETENTION

\begin{tabular}{l|l|l|l}
\hline Group & Mean & SD & t-value \\
\hline Control $(\mathrm{n}=40)$ & 14.3 & 3.9 & \multirow{2}{*}{0.88} \\
\hline Experimental $(\mathrm{n}=43)$ & 13.3 & 6.3 & \\
\hline
\end{tabular}

As shown in Table (1) above, there were no statistically significant differences at alpha (0.01) between mean scores of control students and experimental students on the vocabulary knowledge and retention test, indicating group equivalence prior to the onset of the study. To control for group equivalence, a t-test was calculated to compare mean scores of both groups on pretesting the participants' attitudes towards the quality of each medium as shown in Table (2) below:

TABLE 2

GROUP EQUIVALENCE OF CONTROL AND EXPERIMENTAL PARTICIPANTS ON EFFECTIVENESS OF EMPLOYING ETYMOLOGICAL ANALYSIS AS A MEDIUM OF VOCABULARY VIA THE ONLINE DICTIONARY

\begin{tabular}{l|l|l|l}
\hline Group & Mean & SD & t-value \\
\hline Control $(\mathrm{n}=40)$ & 78 & 11.6 & 0.76 \\
\hline Experimental $(\mathrm{n}=43)$ & 76 & 11.9 & \\
\hline
\end{tabular}

As shown in Table (2) above, there were no statistically significant differences at alpha (0.01) between mean scores of control students and experimental students on the attitude scale, indicating group equivalence in terms of participants' attitudes prior to the launch of the study.

The experiment was then initiated after group equivalence was achieved on vocabulary aptitude and attitude towards the quality of vocabulary instructional method. The same instructor taught both control and experimental students to control for instructor variables interfering with the results, such as teaching competency, personality traits, etc. The experimental group studied the textbook vocabulary in Vocabulary II using the LMS medium of Blackboard powered by the Online Dictionary available for free on the open Internet, and accessed through Blackboard via a link created by the researcher to new vocabulary items in each lesson. Students in the control group studied Vocabulary II in a traditional fashion of short texts and word lists powered by regular look-ups in a paper dictionary in class and at home, with the effort being mostly on the part of the learners in recognizing words and knowing about their roots from the paper dictionary. The e-learning experimental group learners studied the same course syllabus in an e-learning lab with access to the online dictionary with other hyperlinks to supportive web resources on word roots and etymological analysis of word origins and word roots. Students were guided as to how to use the online dictionary to reach out for the historical development of words, the roots, syllable division, affixes, etc., that are congruous with context. Table (3) below shows the means and standard deviations of both groups upon post-testing; the t-value is also showed, and the gain score has been calculated for both groups for comparison of performance between pretesting and posttesting: 
TABLE 3

MEANS, StANDARD DEVIATIONS, GAIN SCORES, AND T-VALUE OF PRETESTING/POSTTESTING ON TRANSLATION APTITUDES

\begin{tabular}{|c|c|c|c|c|c|}
\hline \multirow[t]{2}{*}{ Groups } & \multicolumn{2}{|c|}{ Aptitude Test } & \multirow[t]{2}{*}{ Mean Gain Score } & \multirow[t]{2}{*}{$S D$} & \multirow[t]{2}{*}{ t-value } \\
\hline & Pretesting & Posttesting & & & \\
\hline Control $(n=40)$ & 14.3 & 19.6 & 5.3 & 5.7 & $2.7^{* *}$ \\
\hline
\end{tabular}

The table above shows t-test results for the differences in mean scores on the vocabulary test for both the control and the experimental groups. Findings showed that there were significant differences between the mean scores to the good of the experimental group. Such findings led the researcher to discard of the first null hypothesis, and conclude that the instructional e-learning medium supported by the Online Dictionary in teaching vocabulary through etymological analysis has been significantly more effective than the traditional method using a paper dictionary and bilingualised word lists.

As for the participants' opinions regarding the effectiveness of employing etymological analysis as a medium of vocabulary, Table (4) below shows the means, gain scores, standard deviations, and t-value of both groups upon postadministration of the attitude scale:

TABLE 4

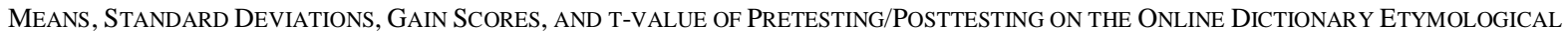
ANALYSIS ATTITUDES

\begin{tabular}{|c|c|c|c|c|c|}
\hline \multirow[t]{3}{*}{ Groups } & \multicolumn{2}{|c|}{ Attitude Scale } & \multirow[t]{3}{*}{ Mean Gain Score } & \multirow[t]{3}{*}{$S D$} & \multirow[t]{3}{*}{ t-value } \\
\hline & Pretesting & Posttesting & & & \\
\hline & Mean score & Mean score & & & \\
\hline Control $(n=40)$ & 78 & 87.2 & 9.2 & 18.2 & \multirow[t]{2}{*}{$2.48^{*}$} \\
\hline Experimental $(n=43)$ & 76 & 93.4 & 17.4 & 10.8 & \\
\hline
\end{tabular}

The table above shows t-test results for the differences in mean scores on the attitude scale for both the control and the experimental groups. Findings showed that there were significant differences between the mean scores to the good of the experimental group. Again, these findings led the researcher to reject the second null hypothesis, and conclude that the instructional e-learning medium supported by the Online Dictionary has been significantly more favourable to, and conducive to positive attitudes in the EFL students than the traditional method of paper dictionaries and word lists.

\section{DISCUSSION}

The results of this study showed that there were significant differences between the experimental group participants and the control group participants on pretesting both on performance on the vocabulary knowledge test and the attitudes towards using etymological analysis via the Online Dictionary medium to the advantage of the experimental students. This indicates that vocabulary instruction through the etymological analysis feature of the Online Dictionary proved to be more effective than using paper dictionaries and traditional bilingualised word lists. This study has also proven that the online dictionary as used to support Blackboard software has also proven more effective in developing and brushing up on the skills of etymological analysis in EFL students. A potential reason is the ease of use, and the variety of facilities available on the online dictionary, including web search, thesaurus, and the translator which can help students to identify word syllables and recognize the meanings of affixes as well as recognize the etymological development of English words. Online dictionary and the electronic medium of Blackboard has also provided supportive web resources such as thesauruses and etymology tracers that helped experimental students to learn more about words, their cultural usages, denotations, and connotational loadings of lexicon as well as the word usage in context, which is not often available in paper dictionary based classrooms of translation instruction. This finding is commensurate with prior research in this line (e.g., Aldosari \& Mekheimer, 2010; Ballesteros \& Croft, 2003; Bellomo, 1999; Honglan, 2005; Hosseini, et al., 2012; Hull \& Grefenstetter, 1996; Koren, 1997; Provaznikova, 2009; Sharpe, 1995).

The findings also bore evidence that e-learning of translation, using Blackboard and the online dictionary has been conducive to improved positive attitudes towards translation courses. This is also in line with some prior research which indicated that e-learning can induce to enhanced language learning in the classroom, as well as enhanced positive attitudes towards the coursework learned in a technology-based language classroom (Yan \& Chen, 2007; Huang, Chern \& Lin, 2009).

\section{IMPLICATIONS OF THE STUDY}

Findings from the present study, including the participants' introspective data elicited from the attitude survey support the view that using the etymological analysis, word history maps and etymological traces of studied vocabulary in the Online Dictionary proved effective in meaningful vocabulary learning for EFL students; therefore, etymological analysis can function as an independent technique for vocabulary teaching par excellence. Hence, this technique may be 
recommended for use in vocabulary instruction explicitly and independently or along with other techniques cited in pertinent literature and are deemed to be helpful in the development of vocabulary learning in EFL learners.

Furthermore, as cited earlier, few studies have been conducted regarding teaching etymology in the field of vocabulary teaching and learning. Thus, further research studies concerning vocabulary instruction are needed in the area of second/foreign language learning.

The findings of the present study provide instructional designers and instructors guided advice and useful pedagogical implications for utilizing hyperlinked dictionaries with online materials and furnishes them with guided training on the use of etymological analysis using the Online Dictionary. The Online Dictionary website can be harnessed to create hyperlinks to all the words in an e-text in order to provide an easily accessible, hyperlinked dictionary in a seamless, non-distracting manner; this can be especially helpful for learners in terms of efficacy and motivation for vocabulary learning. While prior research on glossing (hyperlinking) tested mainly its effect on comprehension and vocabulary acquisition retention (Dwight, 2003; Lomika, 1998; Nikolova, 2004) as well as reading avoidance (Vacca, 2006), very few studies investigated the efficacy of etymological analysis in improving vocabulary learning and attitudes towards vocabulary instruction (Hosseini, et al., 2012).

While this study could demonstrate overall increases in vocabulary learning and improved attitudes towards using the Online Dictionary for learning word etymologies using the hyperlinked dictionary, the findings of the present study encourage the conducting of additional research for a larger population, additional groups, and longitudinal research designs. Further research should include populations that begin with lower language proficiency to aid in demonstrating significant increases in vocabulary learning, attitude improvement and motivation increment.

Future studies may also be needed to use passages from widely used textbooks that are written and approved as college reading level through editing, hyperlinking and glossing using the Online Dictionary with emphasis on word etymology training in online learning settings. Likewise, future studies might want to focus on non-native pre-college students because they would be less likely to be well-versed in strategy-based vocabulary instruction.

In addition, future studies might also want to control for a type of halo-type 3effect and seek to answer the question: "Does the presence of a hyperlinked dictionary, even in cases in which it is not used for reading online, contribute to improved explicit vocabulary learning via etymological analysis and improved attitudes towards vocabulary learning?" Future research might observe how students use the hyperlinked glosses and document the process. This technique can provide insightful implications into how hyperlinking affects increased vocabulary learning. Is it the fact that the online hyperlinking courseware is simply there or is it the fact that they use it which influences an increase in incidental vocabulary learning and improved attitudes and motivation? Can reading online with a hyperlinked dictionary ease the reading process enough to significantly increase efficacy in explicit vocabulary learning?

Future researchers can also use other research methodologies like qualitative tools. Case studies, textual analysis of answers to a series of open-ended questions or written reflections, can offer additional insightful pedagogical implications into how etymological analysis influences attitudes towards online reading, efficacy, and motivation to tackle reading perceived as more difficult than reading skills levels. As well, researchers can investigate the learning gains on vocabulary learning by using an online hyperlinked text with training on etymological analysis and semantic mapping. Does it create enough benefit to invest the amount of time and effort to deliver such a system to students?

\section{REFERENCES}

[1] Ahmed, M.O. (1989). Vocabulary learning strategies. London: British Association for Applied Linguistics in association with Centre for Information on Language Teaching and Research.

[2] Aldosari, H. \& Mekheimer, M. (2010). Utilisation of English-English Online Dictionaries for Enhancing Culture-specific Translation Skills in College Students. Paper Presented at the International Conference of Suleyman Demirel University on "Building cultural bridges: Integrating Languages, Linguistics, Literature and Translation into Education", ALMATY - April 23 - 24, 2010, pp. 545-552.

[3] Allen, F.V. (1983). Techniques in teaching vocabulary. Oxford: OUP.

[4] Anglin, J. M. (1993). Vocabulary development: A morphological analysis. Monographs of the Society for Research in Child Development, 58(10, Serial No. 238).

[5] Aweiss, S. (1994). Situated learning in technology: The case of computer-mediated reading supports. Journal of Educational Technology Systems, 23, 63-74.

[6] Baleghizadeh, S., \& Yousefpoori Naeim. M. (2011). Enhancing vocabulary retention through semantic mapping: A single subject study. The International Journal of Language Society and culture. (32), 11-6.

[7] Ballesteros, L., \& Croft, W. (2003). Phrase Translation and Query Expansion Techniques for Cross-Language Information Retrieval. SIGIR'03.

[8] Bellomo, T. S. (1999). Etymology and vocabulary development for the L2 college student. Teaching English as a Second or Foreign Language, 4(2), 1-2.

[9] Biemiller, A., \& Slonim, N. (2001). Estimating root word vocabulary growth in normative and advantaged populations: Evidence for a common sequence of vocabulary acquisition. Journal of Educational Psychology, 930), 498-520.

[10] Biemiller, A. (2005). Size and sequence in vocabulary development: Implications for choosing words for primary-grade vocabulary instruction. In A. Hiebert \& M. Kamil (Eds.), Teaching and learning vocabulary: Bringing research to practice (pp. 223-242). Mahwah, NT: Erlbaum. 
[11] Biemiller, A. (2006). Vocabulary development and instruction: A prerequisite for school learning. In S. Neuman \& D. Dickinson (Eds.), Handbook of early literacy research (Vol. 2, pp. 41-51). New York, NY: Guilford Press.

[12] Catalán, R. (2003). Sex differences in L2 vocabulary learning strategies. International Journal of Applied Linguistics, 13, 5477.

[13] Chen, Y (2011). Dictionary use and vocabulary learning in the context of reading. International Journal of Lexicography, 25(2), 216-247.

[14] Chun, D., \& Plass, J. (1996). Effects of multimedia annotations on vocabulary acquisition. Modern Language Journal, 80 (2), 183-198.

[15] Coady J. (1997). L2 vocabulary through extensive reading. In J. Coady \& A. Huckin (Eds.), Second-language vocabulary acquisition: A rationale for pedagogy (pp. 225-237). Cambridge, England: Cambridge University Press.

[16] Craik, F.I.M. and Lockhart, R.S. (1972). Levels of processing: a framework for memory research. Journal of Verbal Learning and Verbal Behavior, 11, 671-84.

[17] Dwight, J. (2003, June). A manifesto for instructional technology: hyper. Teachers College Record, 105(5), 669-728.

[18] Dziemianko, A (2011), Does dictionary form really matter? In A. Kaoru \& S. Uchida (Eds.), Asialex 2011: Proceedings, lexicography: Theoretical and practical perspectives (pp. 92-101). Kyoto, Japan: Asian Association of Lexicography.

[19] Dziemianko, A. (2010). Paper or electronic? The role of dictionary form in language reception and the retention of meaning and collocation. International Journal of Lexicography, 23(5), 257-254.

[20] Fan, M. (2003). Frequency of use, perceived usefulness, and actual usefulness of second language vocabulary strategies: a study of Hong Kong learners. Modern Language Journal, 87, 222-41.

[21] Folse, K.S. (2004). Vocabulary myths: applying second language research to classroom teaching. Ann Arbor, MI: University of Michigan Press.

[22] Gettys, S., Imhof, A., \& Kautz, J. (2001). Computer-assisted reading: The effect of glossing format on comprehension and vocabulary retention. Foreign Language Annals, 34(2), 91-99.

[23] Gu, Y. (2003). Fine brush and freehand: the vocabulary-learning art of two successful Chinese EFL learners. TESOL Quarterly, 37, 73-104.

[24] Gu, Y. and Johnson, R.K. (1996). Vocabulary learning strategies and language learning outcome. Language Learning, 46, 64379.

[25] Honglan, J. (2005). Using Web Resources for Effective English-to-Chinese Cross Language Information Retrieval. Unpublished PhD, The Chinese University of Hong Kong.

[26] Hosseini, E., Sarfallah, S., Bakhshipour, F., \& Dolatabadi, H. (2012). The Impact of Using Etymological Analysis on Teaching Vocabulary to EFL University Students. Theory and Practice in Language Studies, 2 (9), 1868-1876.

[27] Huang, H., Chern, C. \& Lin, C. (2009). EFL learners' use of online reading strategies and comprehension of texts: An exploratory study. Computers \& Education, 52, 13-26.

[28] Hull, D.A., and Grefenstetter, G. (1996). Querying across languages: A dictionary-based approach to multilingual information retrieval. In Proceedings of the $19^{\text {th }}$ International Conference on Research and Development in Information Retrieval, 49-57.

[29] Ji, X. H. (2009). Study of contextual guessing and dictionary consulting in incidental vocabulary learning through reading. Unpublished master's dissertation, China University of Petroleum, Shangdong.

[30] Jian, H-L, Sandnes, F. E., Law, K. M. Y, Yo-Ping Huang, Y-R \& Huang, Y M. (2009). The role of electronic pocket dictionaries as an English learning tool among Chinese students. Journal of Computer Assisted Learning, 25(6), 503-514

[31] Kent, D. (2001). Korean university freshmen's dictionary use and perceptions regarding dictionaries. Korea TESOL Journal, 4(1), 73-92.

[32] Knight, S. (1994). Dictionary: The tool of last resort in foreign language reading? Modern Language Journal, 78(3), $285-299$.

[33] Koga, Y (1995). The effectiveness of using an electronic dictionary in second-language reading. Bulletin of Liberal Arts of Hiroshima University, 44, 239-244.

[34] Kojic-Sabo, I. and Lightbown, P.M. (1999). Students' approaches to vocabulary learning and their relationship to success. Modern Language Journal, 83, 176-92.

[35] Koponen, A. (2012). Student Self-Reported Reading Efficacy Using a Text Hyperlinked to an Online Dictionary. Unpublished Doctoral Dissertation. College of Education and Behavioral Sciences Department of Educational Technology: University of Northern Colorado. UMI Number: 3541967.

[36] Koren, S. (1997). Quality versus Convenience: Comparison of Modern Dictionaries from the Researcher's, Teacher's and Learner's Points of View. TESOL-EJ, 2(3), 1-16.

[37] Laufer, B. (2001). Reading, word -focused activities, and incidental vocabulary acquisition in a second language. Prospect, 16(3), 44-54.

[38] Laufer, B., \& Hadar, L. (1997). Assessing the effectiveness of monolingual, bilingual, and bilingualised dictionaries in the comprehension and production of new words. Modern Language Journal, 81, 189-196.

[39] Laufer, B., \& Rimmel, M. (1997). Bilingual dictionaries: How learners really use them. System, 25(3), 361-369.

[40] Lawson, J.M. and Hogben, D. (1996). The vocabulary learning strategies of foreign-language students. Language Learning, 46, 101-35.

[41] Lomika, L. (1998). To gloss or not to gloss: An investigation of reading comprehension online. Language Learning and Technology, 1, 41-50.

[42] Lyman-Hager, M., Davis, N., Burnett, J., \& Chennault, R. (1993). Une vie de boy: Interactive reading in French. In F. L. Borchardt \& E.M.T. Johnson (Eds.), Proceedings of CALICO 1993 annual symposium on assessment (pp. 93-97). Durham, NC: Duke University.

[43] McDonough, S.H. (1999). Learner strategies: state of the art article. Language Teaching, 32, 1-18.

[44] Mekheimer, M. (2012). Assessing Aptitude and Attitude Development in a Translation Skills Course. CALICO Journal, 29(2), p-p 321-340.

[45] Nakamura, T. (2002). Vocabulary learning strategies: the case of Japanese learners of English. Kyoto: KoyoShobo. 
[46] Nikolova, O. (2004, Nov 1). Effects of visible and invisible hyperlinks on vocabulary acquisition and reading comprehension for high-and average-foreign language achievers. Apprentissage des langues et systèmes d'information et de communication (ALSIC), 7, 29-53.

[47] Noor, N. M. (2011). Reading habits and preferences of EFL postgraduates: A case study Indonesian Journal of Applied Linguistics, 1(1), 1-9.

[48] Nyikos, M. and Fan, M. (2007). A review of vocabulary learning strategies: Focus on language proficiency and learner voice. In Cohen, A. and Macaro, E. (Eds.), Language learning strategies: thirty years of research and practice (pp. 251-74). Oxford: Oxford University Press.

[49] Paul, R (1996). Reading vocabulary knowledge and deafness. Journal of Deaf Studies and Deaf Education, 1(1), 3-15.

[50] Provaznikova, L. (2009). The effects of online previewing activities on the comprehension of authentic video and on short-term vocabulary retention. Unpublished $\mathrm{PhD}$, The University of Iowa.

[51] Rasekh, Z.E. and Ranjbary, R. (2003). Metacognitive strategy training for vocabulary learning. TESOL-EJ, 7(2), 1-5. Retrieved January $3^{\text {rd }} 2014$, from http://www-writing.berkeley.edu/tesl-ej/ej26/a5.html.

[52] Sanaoui, R. (1995). Adult learners' approaches to learning vocabulary in second languages. Modern Language Journal, 79, 1528.

[53] Schmitt, N. (1997). Vocabulary learning strategies. In Schmitt, N. and McCarthy, M. (Eds.), Vocabulary: description, acquisition and pedagogy (pp. 199-227). Cambridge: Cambridge University Press.

[54] Schmitt, N. (2008). Instructed second language vocabulary learning. Language Teaching Research, 12, 329-63.

[55] Sharpe, P. (1995). Electronic dictionaries with particular reference to the design of an electronic bilingual dictionary for English-speaking learners of Japanese. International Journal of Lexicography, 8 (1), 39-54.

[56] Shi, Z. L. (2008). A comparative study of three learning strategies in EFL students' incidental vocabulary acquisition. CRI. FA Journal, 31(6), 91-101.

[57] Solomon, G. (2002). Digital equity: It's not just about access anymore. Technology and Learning, 22, 18-26.

[58] Stahl, S. (1999). Vocabulary development. Cambridge, MA: Brookline Books.

[59] Tompkins, G. (2005). Language arts: Patterns of practice. (6 ${ }^{\text {th }}$ ed.). Columbus, OH: Pearson: Merrill Prentice Hall.

[60] Trench, R. (1998). The study of words. London: John Parker.

[61] Vacca, R. (2006, Feb.). They can because they think they can. Educational Leadership, 63(5), 56-59.

[62] Wang, J. (2011). The use of e-dictionary to read e-text by intermediate and advanced learners of Chinese. Computer Assisted Language Learning, 24(1), 1-13.

[63] Welker, H. A. (2010). Dictionary use: A general survey of empirical studies. Brasilia, Brazil: Author's Edition.

[64] Yang, S. \& Chen, Y. (2007). Technology-enhanced language learning: A case study. Computers in Human Behavior, 23, 860879.

[65] Zaid, M. A. (2009). A Comparison of Inferencing and Meaning-guessing of New Lexicon in Context versus Non-context Vocabulary Presentation. The Reading Matrix, 9 (1), 56-66.

[66] Zaki, H. and Ellis, R. (1999). Learning vocabulary through interacting with a written text. In Ellis, R. (Ed.), Learning a second language through interaction (pp. 153-69). Amsterdam: John Benjamins.

[67] Zhang, L. (2000). Study of incidental vocabulary of Chinese intermediate English learners. Unpublished master's dissertation, Shanghai Jiao Tong University, Shanghai, China.

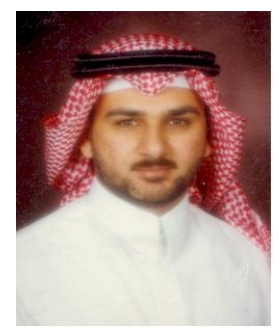

Abdulaziz Ibraheem Fageeh, MA in TESOL from Michigan State University, Michigan, East Lansing, USA 1994, PhD in Applied Linguistics from Indiana University of Pennsylvania, USA, 2003, is currently an associate professor of applied linguistics in the English Department, Faculty of Languages \& Translation, Abha, King Khalid University. At present, he is the dean of the Faculty of Sciences \& Arts at Tanouma, King Khalid University. His research interests include e-learning, writing research, cognitive processes in reading, training and neuro-linguistic programming. 